\title{
Perspectives of Photodynamic Therapy (PDT) as a Potential Therapeutic Intervention for Câncer
}

\author{
Fernanda Malagutti Tomé*, Simone Aparecida Biazzi de Lapena, Wendel Simoes Fernandes, Adriano \\ Moraes da Silva and Fernanda Sant'ana de Siqueira e Oliveira
}

Universidade Paulista-UNIP, Brazil

*Corresponding author: Fernanda Malagutti Tomé, Universidade Paulista-UNIP,

Received Date: April 01, 2019

Brazil.

\begin{abstract}
Photodynamic therapy (PDT) relies on the interaction between a photosensitizer, the appropriate wavelength, and oxygen leading to production of cytotoxic reactive oxygen species, which can damage the cellular organelles and cause cell death. Photodynamic therapy (PDT) is a tumor-ablative and function-sparing oncologic intervention. The relative simplicity of photosensitizer application followed by light activation resulting in the cytotoxic and vascular toxic photodynamic reaction has allowed PDT to reach a worldwide audience. With several commercially available photosensitizing agents now on the market, numerous well-designed clinical trials have demonstrated the efficacy of PDT on various cutaneous and deep tissue tumors. PDT has been widely used for many purposes' great success. Although the therapeutic protocols regarding use of PDT in many diseases have not yet been standardized, and vary significantly between the different literature studies, PDT will likely continue to be explored thoroughly for use.
\end{abstract}

Keywords: Photodynamic therapy; Tumor; Cell death

\section{Introduction}

Photodynamic therapy (PDT) relies on the interaction between a photosensitizer, the appropriate wavelength, and oxygen leading to production of cytotoxic reactive oxygen species, which can damage the cellular organelles and cause cell death. First introduced about 100 years ago, PDT has continued to evolve in dermatology into a safe and effective treatment option for several dermatologic conditions. PDT is also used by pulmonologists, urologists, ophthalmologists gynecologics, gastroenterologics and denstists. PDT basically requires three separate components: a nontoxic dye, termed a photosensitizer (PS); a low intensity of visible light; and a diseased "target cell or tissue" containing sufficient oxygen. A photochemical reaction takes place between these three components leading to the generation of cytotoxic reactive oxygen species (ROS) and consequently to cell and tissue destruction. Two complementary photochemical reactions can take place from the long-lived triplet excited-state of the PS (3PS*). Firstly, in a Type 1 reaction, the 3PS can react directly with a substrate (often oxygen) undergoing an electron transfer reaction initially producing free radicals that may further react with oxygen to produce ROS (including hydroxyl radicals). Alternatively, in Type 2 reaction, the PS can transfer its energy directly to ground state (triplet) molecular oxygen to form excited-state singlet oxygen (also a ROS). Both Type 1 and Type 2 reactions can occur simultaneously. On the cellular level, the mitochondrial pathway is the most likely mechanism by which PDT induces oxidative damage in the target cells, leading to induction of apoptosis. [1] Enthusiasm for photodynamic therapy (PDT) as a potential therapeutic intervention for cancer has increased exponentially in recent decades. The overall efficiency of PDT depends on characteristics of activation light and in-situ dosimetry, including the choice of photosensitizer molecule, wavelength of the light, and tumor location and microenvironment. Successful PDT depends on the choice of PS, appropriate excitation light, and tumor type. Note that biological components have less absorption in the region between 600 and $1200 \mathrm{~nm}$; light at this region can deeply penetrate biological tissue. Otherwise most PSs are activated at 600-700 $\mathrm{nm}$. The conventional PDT uses PS, which is activated by this activation wavelength and suffers from poor penetration depth, and thus its application is limited to superficial tumors. 


\section{Photodynamic Therapy Applied to Cancer}

Photodynamic therapy (PDT) is a tumor-ablative and function-sparing oncologic intervention. The relative simplicity of photosensitizer application followed by light activation resulting in the cytotoxic and vascular toxic photodynamic reaction has allowed PDT to reach a worldwide audience. With several commercially available photosensitizing agents now on the market, numerous well-designed clinical trials have demonstrated the efficacy of PDT on various cutaneous and deep tissue tumors. However, current photosensitizers and light sources still have a number of limitations. Future PDT will build on those findings to allow development and refinement of more optimal therapeutic agents and illumination devices [2]. The table 1 shows the current state of the art of PDT, and highlight the progress being made towards the future of oncologic PDT (Table 1).

Table 1: Some examples of PDT studies.

\begin{tabular}{|c|c|c|}
\hline Reference & Type of Study & Conclusion \\
\hline Kofler et al. [3] & $\begin{array}{l}\text { The effect of PDT with methylene blue (MB) and a diode laser (660 } \\
\mathrm{nm} \text { ) as the laser source on HNSCC cell lines as an in vitro model of } \\
\text { surface oral squamous cell carcinoma }\end{array}$ & $\begin{array}{l}\text { Multiresistant cells expressing cancer stem cell } \\
\text { markers are sensitive to MB/red laser combined } \\
\text { PDT. }\end{array}$ \\
\hline Shen et al. [4] & $\begin{array}{c}\text { To investigate the antitumor effects and underlying mechanisms } \\
\text { of (17R,18R)-2-(1-hexyloxyethyl)-2-devinyl chlorine E6 trisodium } \\
\text { salt (YLG-1)-induced photodynamic therapy (PDT) on pancreatic } \\
\text { cancer in vitro and in vivo. }\end{array}$ & $\begin{array}{c}\text { YLG-1 is a potential photosensitizer for pancreatic } \\
\text { cancer PDT via IT injection, the mechanisms } \\
\text { of which are associated with inducing ROS and } \\
\text { promoting apoptosis. }\end{array}$ \\
\hline Austin et al. [5] & $\begin{array}{l}\text { Incubated two cell lines with 5-ALA for } 30 \text { minutes at temperatures } \\
\text { between } 21^{\circ} \mathrm{C} \text { and } 42^{\circ} \mathrm{C} \text { and then irradiated cells with } \\
1000 \text { seconds of blue light and measured changes in apoptosis, } \\
\text { necrosis, and ROS. }\end{array}$ & $\begin{array}{l}\text { Increased cell apoptosis and ROS generation } \\
\text { compared to untreated control samples incubated } \\
\text { at the same temperatures. Thermal PDT may } \\
\text { represent a new treatment option for cutaneous } \\
\text { and mucosal SCC cancer }\end{array}$ \\
\hline Jiang et al. [6] & $\begin{array}{c}\text { Protoporphyrin IX is a dual inhibitor of p53/MDM2 and p53/ } \\
\text { MDM4 interactions and induces apoptosis in B-cell chronic } \\
\text { lymphocytic leukemia cells }\end{array}$ & $\begin{array}{l}\text { Study demonstrates that PpIX is a potent activator } \\
\text { of p53 and TAp73 in B-CLL. Our findings might } \\
\text { speed up repurposing of PpIX in treating cancers } \\
\text { containing wt-p53 and TAp73 and with high } \\
\text { expression of MDM2 and MDM4 oncogenes. }\end{array}$ \\
\hline
\end{tabular}

\section{Conclusion}

PDT has been widely used for many purposes' great success. Although the therapeutic protocols regarding use of PDT in many diseases have not yet been standardized, and vary significantly between the different literature studies, PDT will likely continue to be explored thoroughly for use. Nevertheless, it is recommended that physicians should always employ careful assessment of protocols and individual patients and educate patients with regard to realistic outcomes and proper precautions especially in oncology.

\section{Acknowledgment}

None.

\section{Conflict of Interest}

No conflict of interest.

\section{References}

1. Wen X, Li Y, Hamblin MR (2017) Photodynamic therapy in dermatology beyond non-melanoma cancer: An update. Photodiagnosis Photodyn Ther 19: 140-152.
2. Ben Mihoub A, Larue L, Moussaron A, Youssef Z, Colombeau L, et al. (2018) Use of Cyclodextrins in Anticancer Photodynamic Therapy Treatment. Molecules 23(8): 1936.

3. Kofler B, Romani A, Pritz C, Steinbichler TB, Schartinger, et al. (2018) Photodynamic Effect of Methylene Blue and Low-Level Laser Radiation in Head and Neck Squamous Cell Carcinoma Cell Lines. Int J Mol Sci 19(4): E1107.

4. Shen YJ, Cao J, Sun F, Cai XL, Li MM, et al. (2018) Effect of photodynamic therapy with (17R,18R)-2-(1-hexyloxyethyl)-2-devinyl chlorine E6 trisodium salt on pancreatic cancer cells in vitro and in vivo. World J Gastroenterol 24(46): 5246-5258.

5. Austin E, Koo E, Jagdeo J (2018) Thermal photodynamic therapy increases apoptosis and reactive oxygen species generation in cutaneous and mucosal squamous cell carcinoma cells. Sci Rep 8(1): 12599.

6. Jiang L, Malik N, Acedo P, Zawacka-Pankau J (2019) Protoporphyrin IX is a dual inhibitor of p53/MDM2 and p53/MDM4 interactions and induces apoptosis in B-cell chronic lymphocytic leukemia cells. Cell death discovery 5: 77. 